\title{
Produtividade da cana-de-açúcar relacionada ao nitrogênio residual da adubação e do sistema radicular
}

\author{
André Cesar Vitti ${ }^{(1)}$, Paulo Cesar Ocheuze Trivelin(1), Glauber José Castro Gava ${ }^{(2)}$, Claudimir Pedro Penatti( ${ }^{(3)}$, \\ Isabela Rodrigues Bologna ${ }^{(1)}$, Carlos Eduardo Faroni ${ }^{(1)}$ e Henrique Coutinho Junqueira Franco ${ }^{(1)}$
}

(1)Centro de Energia Nuclear na Agricultura, Av. Centenário, no 303, Caixa Postal 96, CEP 13400-970 Piracicaba, SP. E-mail: acvitti@cena.usp.br,
pcotrive@cena.usp.br, irbologn@carpa.ciagri.usp.br, cfaroni@cena.usp.br, hifranco@cena.usp.br (2)APTA Regional, Pólo Regional de
Desenvolvimento do Centro Oeste Paulista, Caixa Postal 96, CEP 17340-000 Jaú, SP. E-mail: ggava@aptaregional.sp.gov.br (3)Centro de
Tecnologia Canavieira, Faz. Santo Antônio, Bairro Santo Antônio, Caixa Postal 0162, CEP 13400-970 Piracicaba, SP. E-mail: claudimir@ctc.com.br

Resumo - O trabalho foi desenvolvido, durante duas safras agrícolas, com colheita da cana-de-açúcar sem queima, a fim de avaliar o efeito residual da adubação nitrogenada da $2^{\underline{a}}$ soca (safra 1999/2000), e o efeito do $\mathrm{Ne}$ S do sistema radicular da cultura na produtividade do ciclo agrícola subseqüente (3aㅗ soca - safra 2000/2001). O delineamento experimental foi em blocos ao acaso com seis tratamentos e quatro repetições. Os tratamentos da safra 1999/2000 foram 0, 35, 70,105, 140 e $175 \mathrm{~kg} \mathrm{ha}^{-1} \mathrm{de} \mathrm{N}$ com a fonte nitrato de amônio, aplicada sobre a palha. Na $3^{\underline{a}}$ soca aplicaram-se $100 \mathrm{~kg} \mathrm{ha}^{-1} \mathrm{de} \mathrm{N}$ em todos os tratamentos da safra anterior ( $2^{\underline{a}}$ soca). Nas parcelas, no primeiro ano, foram inseridas microparcelas que receberam o fertilizante nitrato de amônio marcado em ${ }^{15} \mathrm{~N}$ na fração amônio. As doses de $\mathrm{N}$ proporcionam efeito linear altamente significativo na produtividade de colmos da $2^{\underline{a}}$ soca e esse efeito mantém-se na $3^{\underline{a}}$ soca, mesmo sendo aplicada uma única dose de $\mathrm{N}$; a adubação nitrogenada e o conteúdo de $\mathrm{N}$ e $\mathrm{S}$ do sistema radicular correlacionam-se positivamente com a produtividade da cana-deaçúcar na safra seguinte.

Termos para indexação: Saccharum, isótopo ${ }^{15} \mathrm{~N}$, nitrato de amônio, enxofre, soqueira.

\section{Sugar cane yield related to the residual nitrogen from fertilization and the root system}

\begin{abstract}
The work was carried out between two harvesting seasons, without burn, to evaluate the residual effect of the nitrogen fertilization on the $2^{\text {nd }}$ ratoon crop of sugar cane (harvest 1999/2000), and the effect of $\mathrm{N}$ and S content in the root system on the following productivity of the next cycle ( $3^{\text {rd }}$ ratoon crop - harvest 2000/2001). The experiment design was in randomized blocks with six treatments and four replications. The harvest 1999/2000 treatments were $0,35,70,105,140$ and $175 \mathrm{~kg} \mathrm{ha}^{-1}$ of $\mathrm{N}$ as ammonium nitrate), which was applied over the stove. In the $3^{\text {rd }}$ ratoon crop $100 \mathrm{~kg} \mathrm{ha}^{-1}$ of $\mathrm{N}$ were applied in all the treatments of the previous harvest season. The first year plots contained microplots, which received the ammonium nitrate labeled with ${ }^{15} \mathrm{~N}$ in the ammonium fraction. $\mathrm{N}$ doses showed high significant linear effect in the cane production of the $2^{\text {nd }}$ ratoon crop as well as on the next harvest season ( $3^{\text {rd }}$ ratoon crop) even applied in a unique $\mathrm{N}$ dose; nitrogen fertilization and $\mathrm{N}$ and $\mathrm{S}$ content of the root system were positively related with the sugar cane productivity in the next harvest season.
\end{abstract}

Index terms: Saccharum, isotope ${ }^{15} \mathrm{~N}$, ammonium nitrate, sulfur, ratoon crop.

\section{Introdução}

A cana-de-açúcar é uma cultura semiperene por possibilitar várias colheitas ou cortes depois de cada reforma realizada no canavial. Sob este aspecto, devemse examinar os benefícios que as adubações e a palha deixada na superfície do solo, após as colheitas sem queima, poderão proporcionar com o passar do tempo.
Na maioria dos estudos de resposta à adubação com nitrogênio em cana-de-açúcar, tanto em cana-planta quanto em soqueiras, as fertilizações foram avaliadas pela produção apenas no ciclo agrícola ou ano-safra em que a adubação foi realizada. A cana-de-açúcar vem sendo considerada uma cultura anual, com raros trabalhos como o de Orlando Filho et al. (1999), que mantiveram as parcelas experimentais por quatro anos 
consecutivos no campo. Nesse trabalho foi avaliado o efeito cumulativo de adubações com doses crescentes de N, 0, 60 e $120 \mathrm{~kg} \mathrm{ha}^{-1}$, com uréia, URAN e nitrato de amônio, na produtividade da cana-planta e três socas consecutivas, obtendo-se aumento de 20 e $30 \%$ para doses de 60 e $120 \mathrm{~kg} \mathrm{ha}^{-1}$ de N, respectivamente, em relação à testemunha. Malavolta (1994) menciona resultados não publicados, nos quais verificou o efeito indireto da adubação nitrogenada no plantio da canade-açúcar na produtividade das rebrotas.

Os técnicos que trabalham em usinas produtoras de cana sabem que se não for feita a adubação dos canaviais (soqueiras) com $\mathrm{N}$ em determinado ano, a produtividade naquela safra não será afetada de forma marcante, mas o efeito ocorrerá nos anos seguintes, com reflexo na longevidade da soqueira. Orlando Filho et al. (1999) constataram esse efeito e afirmaram que a resposta da cana-planta ao $\mathrm{N}$ se refletiu no maior vigor das soqueiras, aumentando a produção nos cortes subseqüentes, entre a cana-de-açúcar com adubação e sem adubação nitrogenada. O manejo inadequado de um canavial, especialmente da adubação nitrogenada, pode resultar tanto em redução da produtividade da cultura quanto na sua longevidade, reduzindo, por conseguinte, o número de colheitas ou cortes entre as reformas.

O objetivo deste trabalho foi avaliar o conteúdo de $\mathrm{N}$ e $\mathrm{S}$ do sistema radicular de uma soqueira de cana-de-açúcar em canavial sem queima, e o efeito residual da adubação nitrogenada (safra 1999/2000) na produtividade da cultura no ciclo subseqüente (safra 2000/2001).

\section{Material e Métodos}

O experimento foi conduzido em campo nos anos agrícolas 1999/2000 e 2000/2001. A implantação foi realizada em uma área comercial de cana-de-açúcar de terceiro corte (2 ${ }^{\mathrm{a}}$ soca - safra 1999/2000), colhida mecanicamente e sem a prévia despalha a fogo. A área de produção pertence à Usina São Luiz (Grupo Dedini/S.A.), situada no Município de Pirassununga, SP, a 21 255'54"S e $47^{\circ} 10^{\prime} 54^{\prime \prime} \mathrm{W}$.

A cultivar de cana-de-açúcar utilizada foi SP 81-3250, com aceitação por suas características agronômicas, de bom desenvolvimento em ambiente de produção de média a baixa fertilidade do solo, alto teor de açúcar e produtividade.
O solo do ensaio foi classificado como Neossolo Quartzarênico (Embrapa, 1999) (composição granulométrica de 861 e $139 \mathrm{~g} \mathrm{~kg}^{-1}$, respectivamente, de areia e argila) cujas características químicas de amostras obtidas na camada de $0-20 \mathrm{~cm}$ e nas entrelinhas da cultura foram: $\mathrm{pH}\left(\mathrm{CaCl}_{2}\right) 5,2 ; 7,0 \mathrm{mg} \mathrm{dm}^{-3} \mathrm{de}$ $\mathrm{P}$ (resina); 8,0 mg dm${ }^{-3} \mathrm{de} \mathrm{S} \mathrm{SO}_{4}{ }^{-2} ; 0,5 \mathrm{mmol}_{\mathrm{c}} \mathrm{dm}^{-3} \mathrm{de}$ $\mathrm{K} ; 14,0 \mathrm{mmol}_{\mathrm{c}} \mathrm{dm}^{-3}$ de Ca; 4,0 $\mathrm{mmol}_{\mathrm{c}} \mathrm{dm}^{-3} \mathrm{de} \mathrm{Mg}$; $37,5 \mathrm{mmol}_{\mathrm{c}} \mathrm{dm}^{-3}$ de CTC e $50 \%$ de V. Nas camadas do solo de $40-60 \mathrm{~cm}$ e de $60-80 \mathrm{~cm}$, os teores de $\mathrm{S}$ na forma de $\mathrm{SO}_{4}^{-2}\left(\mathrm{~S}_{-} \mathrm{SO}_{4}{ }^{-2}\right)$ foram, respectivamente, de 25 e $50 \mathrm{mg} \mathrm{dm}^{-3}$. Antes da instalação do experimento, o solo apresentava cobertura de palha de $14 \mathrm{t} \mathrm{ha}^{-1} \mathrm{de}$ matéria seca, contendo $62 \mathrm{~kg}$ de $\mathrm{N}$.

O delineamento experimental foi em blocos ao acaso com seis tratamentos e quatro repetições. O primeiro ano do experimento ( $2^{\mathrm{a}}$ soca - safra 1999/2000) constou de cinco doses de $\mathrm{N}: 35,70,105,140$ e $175 \mathrm{~kg} \mathrm{ha}^{-1}$, com a fonte nitrato de amônio (NA) aplicada em faixa, nos dois lados da linha de cana-de-açúcar, e sobre a palha. Incluiu-se um tratamento testemunha sem fertilização com $\mathrm{N}$ mineral. No primeiro ano, dentro de cada parcela, foram instaladas microparcelas, que receberam os fertilizantes marcados em ${ }^{15} \mathrm{~N}$. Na safra seguinte ( $3^{\text {a }}$ soca - safra 2000/2001), o experimento foi reinstalado no mesmo local, preservando-se as localizações das parcelas do ano anterior, mas aplicando dose única de $\mathrm{N}\left(100 \mathrm{~kg} \mathrm{ha}^{-1}\right)$ com a fonte URAN, adubo líquido com $50 \%$ em ambas as formas de uréia e de nitrato de amônio, mesmo nas microparcelas que receberam fertilizante marcado com ${ }^{15} \mathrm{~N}$.

A área de cada parcela foi de $225 \mathrm{~m}^{2}$, constituída de dez segmentos de linhas de soqueira, com $15 \mathrm{~m}$ de comprimento e espaçadas em 1,5 m. As microparcelas apresentaram dimensões de $2 \mathrm{~m}$ de comprimento e $1,5 \mathrm{~m}$ de largura, totalizando $3 \mathrm{~m}^{2}$. A fonte NA teve sua marcação com ${ }^{15} \mathrm{~N}$ apenas no amônio $(3,50 \%$ em átomos). As microparcelas foram cobertas com tela de náilon, com cerca de $3 \mathrm{~cm}$ de diâmetro, a fim de evitar o revolvimento da palha pelo vento, bem como a entrada de outro material externo à área delimitada. Em todas as parcelas, foram aplicados $150 \mathrm{~kg} \mathrm{ha}^{-1} \mathrm{de} \mathrm{K}$, com as fontes de $\mathrm{N}$.

A fim de avaliar a produção de colmos de cana-deaçúcar por hectare $(\mathrm{TCH})$, nas colheitas realizadas em agosto de 2000 e 2001, foram colhidas as plantas de três fileiras paralelas de dois metros cada, e os valores foram expressos em $\mathrm{t} \mathrm{ha}^{-1}$. As análises tecnológicas de colmos foram desenvolvidas no Centro de Tecnologia 
Canavieira, em Piracicaba, SP (Caldas, 1998). A quantidade de açúcares totais, ou a pol da cana (PC em tha ${ }^{-1}$ ), foi obtida pelo produto entre a pol da cana $(\%)$ e a produtividade de colmos $\left(\mathrm{t} \mathrm{ha}^{-1}\right)$, sendo o valor do produto dividido por 100 .

No metro central das microparcelas e na mesma posição nas fileiras adjacentes, realizou-se colheita manual da parte aérea da cana-de-açúcar, conforme método definido por Trivelin et al. (1994), separando-se a planta em folhas secas, ponteiros, colmos e sistema radicular (raízes e rizomas). Colheu-se também toda a palha remanescente da superfície, com pedaços menores de palha misturados ao solo. Esse material foi separado por peneira de malha de $1 \mathrm{~mm}$, quantificando-se, assim, a massa total residual. Depois de homogeneizado, retirouse uma subamostra, que foi moída para determinações do $\mathrm{N}$ total e abundância de ${ }^{15} \mathrm{~N}$, por espectrometria de massa (átomos \%) (Barrie \& Prosser, 1996), quantificando-se o ${ }^{15} \mathrm{~N}$ presente na palha residual. Sua presença na palha residual pode ser decorrente da imobilização do fertilizante pelos microrganismos do solo ou da presença de raízes da cana-de-açúcar marcadas em ${ }^{15} \mathrm{~N}$, que se desenvolveram junto à palha (composição isotópica natural $0,366 \%$ de átomos de ${ }^{15} \mathrm{~N}$ ), respectivamente, resultando em seu enriquecimento.

A cada $20 \mathrm{~cm}$ e até a camada de $40-60 \mathrm{~cm}$, todo o solo foi peneirado na separação do sistema radicular, homogeneizado e amostrado. Nas demais profundidades $(60-80 \mathrm{~cm}$ e $80-110 \mathrm{~cm})$, foram feitas tradagens em seis pontos ao acaso (três em cada lado da linha) na parte central da subparcela, de modo que os procedimentos de coleta fossem sistemáticos em todas as microparcelas. As amostras de solo, depois de secadas ao ar, foram homogeneizadas e moídas finamente em moinhos de bola para posteriores determinações químicas e isotópicas ( $\mathrm{N}$ total e abundância de ${ }^{15} \mathrm{~N}$ em porcentagem de átomos). Simultaneamente determinou-se a umidade do solo. A estratificação do solo em diferentes profundidades teve como objetivo avaliar o efeito residual do fertilizante marcado em ${ }^{15} \mathrm{~N}$, nessas camadas. Colheu-se todo o sistema radicular (colmo subterrâneo-rizomas e raízes) localizado no centro da subparcela com ${ }^{15} \mathrm{~N}$, em trincheira de $1 \mathrm{~m}$ de comprimento por 1,5 $\mathrm{m}$ de largura e $0,6 \mathrm{~m}$ de profundidade.

Depois da colheita, determinou-se a massa úmida de todo o material vegetal: colmo, ponteiro, folha seca e sistema radicular, sendo este anteriormente lavado e secado ao sol. A seguir, cada amostra foi moída em moinho tipo forrageira, e retirada uma subamostra, que foi secada em estufa, 72 horas a $65^{\circ} \mathrm{C}$, determinando-se a umidade desse material. O material seco foi moído em moinho Wiley e nele foram realizadas as determinações químicas de $\mathrm{N}$ total e de abundância de ${ }^{15} \mathrm{~N}$ (porcentagem em átomos de ${ }^{15} \mathrm{~N}$ ) no espectrômetro de massa ANCA/SL, modelo 20/20, no Cena, USP. As determinações de $\mathrm{S}$ total em raízes e rizomas foram feitas no Centro de Tecnologia Canavieira, em Piracicaba, SP (Malavolta et al., 1989).

Considerou-se efeito residual para a produtividade da safra seguinte todo o $\mathrm{N}$ do amônio da fonte NA que ficou no sistema solo, imobilizado na palha e no sistema radicular, bem como o conteúdo de $\mathrm{N}$ e $\mathrm{S}$ do sistema radicular.

As variáveis de respostas - produtividade de colmo e de açúcares totais e recuperação do $\mathrm{N}$ do fertilizante foram submetidas à análise de variância, utilizando o teste $\mathrm{F}$, a $95 \%$ de confiança e sem a transformação de dados. Posteriormente, para as causas de variação significativas, procederam-se análises de regressão para verificar o efeito de doses de $\mathrm{N}$ da fonte nitrato de amônio. As correlações estabelecidas entre a produção de colmos da safra seguinte e o efeito residual do $\mathrm{N}$ do fertilizante no solo, e também o conteúdo de $\mathrm{N}$ e $\mathrm{S}$ do sistema radicular, nas diferentes doses de $\mathrm{N}$, foram efetuadas por ajustes de regressão linear. A significância do valor de $\mathrm{R}$ foi obtida pelo teste $\mathrm{F}$.

\section{Resultados e Discussão}

Houve resposta linear altamente significativa às doses de N na produção de colmos na 2a soca (safra 1999/ 2000) (Tabela 1). Essa resposta se estendeu para a 3a soca (safra 2000/2001), mesmo aplicando dose única de $\mathrm{N}$ (100 $\left.\mathrm{kg} \mathrm{ha}^{-1}\right)$ em todos os tratamentos após a colheita da safra anterior (2 2 soca). O mesmo ocorreu para a produtividade de açúcares totais, pol da cana $\left(\mathrm{t} \mathrm{ha}^{-1}\right)$. Esses resultados foram decorrentes, provavelmente, do efeito residual da adubação, com reflexo no vigor da soqueira de cana-de-açúcar (Malavolta, 1994; Orlando Filho et al., 1999; Trivelin et al., 2002).

Em relação às doses de N, observou-se diferença de $100 \%$, na produção de colmos na $2^{a}$ soca (safra 1999/2000), entre a maior dose e a testemunha $\left(0 \mathrm{~kg} \mathrm{ha}^{-1} \mathrm{de} \mathrm{N}\right)$. Na safra seguinte (3 $3^{\text {a }}$ soca), esse diferencial na produção foi de $50 \%$, mantendo-se resposta linear às doses de $\mathrm{N}$ aplicadas na safra 
anterior (Tabela 1). É possível que a fertilização com $100 \mathrm{~kg} \mathrm{ha}^{-1} \mathrm{de} \mathrm{N}$, após a colheita da $2^{\mathrm{a}}$ soca tenha propiciado recomposição do vigor da soqueira apenas parcial na 3a soca. Essa recomposição apenas parcial foi causada pelo manejo deficiente da adubação nitrogenada na safra anterior, especialmente em tratamentos com doses inferiores a $105 \mathrm{~kg} \mathrm{ha}^{-1}$. Na soma das produções da $2^{\underline{a}}$ e 3 a socas (safras 1999/2000 e 2000/2001), registrou-se diferença de $67 \mathrm{t} \mathrm{ha}^{-1}$ de colmo da maior dose em relação à testemunha. Esse valor é significativo em termos de rentabilidade referente à adubação nitrogenada.

Entre as doses de 70 e $105 \mathrm{~kg} \mathrm{ha}^{-1}$ de N, o aumento de produtividade não foi tão expressivo como nas maiores doses que causaram a resposta linear verificada (Tabela 1). Caso a maior dose do experimento fosse $105 \mathrm{~kg} \mathrm{ha}^{-1} \mathrm{de} \mathrm{N}$, poderia ocorrer falsa interpretação de que a cana-de-açúcar responderia até $70 \mathrm{~kg} \mathrm{ha}^{-1}$ de $\mathrm{N}$, uma vez que os resultados indicariam tendência quadrática. Sob esse aspecto pode-se questionar se não seria necessário aplicar maior dose de $\mathrm{N}$, na implantação da colheita sem queima, para garantir bom vigor das socas, com reduzida dose de $\mathrm{N}$ nos ciclos agrícolas (anos/safras) futuros. Desse modo, a cultura estaria sustentada por um efeito residual, que, em parte, viria do fertilizante e da própria palha deixada na superfície. Chapman et al. (1983), mesmo não observando efeito residual da adubação anterior no rendimento de açúcares no ciclo seguinte, não descartaram a hipótese de que a aplicação contínua e abundante de $\mathrm{N}$ resultaria em acúmulo do nutriente aplicado a ser aproveitada pelas culturas nos ciclos agrícolas subseqüentes.

$\mathrm{O}$ manejo inadequado da adubação nitrogenada em um canavial pode resultar na redução da produtividade da cultura, como visto na safra 1999/2000 nos tratamentos com as doses mais baixas de $\mathrm{N}$, sendo esse efeito propagado para a safra seguinte (2000/2001), mesmo aumentando-se a dose de N. Outro aspecto a considerar é a redução da longevidade do canavial, o que causa a antecipação de sua reforma. Com o retorno da adubação de $100 \mathrm{~kg} \mathrm{ha}^{-1}$ de $\mathrm{N}$, na safra seguinte a produtividade aumentou, porém com ganhos não tão expressivos em comparação às que antecederam o período da redução na aplicação de $\mathrm{N}$.

As melhores produtividades na cultura da cana-deaçúcar são alcançadas nas safras que se sucedem ao plantio (maior potencial produtivo), quando, então, deverá ser recomendada uma fertilização que supra todas as exigências nutricionais, uma vez que, nos demais anos, além do baixo vigor da soqueira, surgem, ou se agravam, problemas relacionados ao nível nutricional, compactação do solo, pragas e doenças. Orlando Filho et al. (1999) observaram queda na produtividade agrícola ao longo dos ciclos, sendo mais drástica da cana-planta (cana de ano e meio) para a primeira soca. Concluíram ainda que a cana-planta e as três soqueiras subseqüentes responderam linearmente à adubação nitrogenada até a dose de $120 \mathrm{~kg} \mathrm{ha}^{-1}$. Chapman et al. (1983) constataram que as soqueiras requerem maior quantidade de $\mathrm{N}$ para produzirem como a cana-planta, provavelmente devido à diminuição das reservas de $\mathrm{N}$ no solo ao longo do ciclo.

A qualidade tecnológica dos colmos nos tratamentos com doses de $\mathrm{N}$ foi superior ao limite considerado adequado para se efetuar a colheita da cana-de-açúcar (Fernandes, 1986). Porém, não houve variação significativa entre os tratamentos nos teores de fibra $(11,9 \%)$

Tabela 1. Nitrogênio da adubação de solo na cana-de-açúcar (2aㅗ soca - safra 1999/2000) na produtividade de colmos (TCH) e de açúcares na 3ª soca (safra 2000/2001).

\begin{tabular}{|c|c|c|c|c|c|c|c|}
\hline \multicolumn{2}{|c|}{ Fontes } & \multicolumn{2}{|c|}{ Doses de N } & \multicolumn{3}{|c|}{$\mathrm{TCH}$} & \multirow{2}{*}{$\begin{array}{c}\text { Açúcar } \\
1999 / 2000+2000 / 2001^{(2)}\end{array}$} \\
\hline $1999 / 2000$ & $2000 / 2001$ & $1999 / 2000$ & $2000 / 2001$ & $1999 / 2000$ & $2000 / 2001^{(1)}$ & $1999 / 2000+2000 / 2001^{(2)}$ & \\
\hline & & \multicolumn{2}{|c|}{------(kg ha' $\left.{ }^{-1}\right)--$} & |------------. & -------------- ( & |---------------------------------- & \\
\hline Testemunha & URAN & 0 & 100 & 40,8 & 58,1 & 98,9 & 15,6 \\
\hline NA & URAN & 35 & 100 & 58,8 & 56,2 & 115,0 & 18,1 \\
\hline NA & URAN & 70 & 100 & 63,3 & 77,5 & 140,8 & 21,6 \\
\hline NA & URAN & 105 & 100 & 65,5 & 78,1 & 143,6 & 22,8 \\
\hline NA & URAN & 140 & 100 & 70,8 & 81,2 & 152,0 & 24,8 \\
\hline NA & URAN & 175 & 100 & 80,4 & 86,3 & 166,7 & 26,3 \\
\hline \multicolumn{2}{|c|}{ Média } & & & 63,2 & 72,9 & 136,1 & 21,5 \\
\hline \multicolumn{2}{|c|}{ Regressão linear } & & & $* *$ & $* *$ & $* *$ & $* *$ \\
\hline \multicolumn{2}{|c|}{ CV $(\%)$} & & & 18,1 & 11,6 & 12,3 & 11,0 \\
\hline \multicolumn{2}{|c|}{$\mathrm{F}_{\text {doses }}$} & & & $* *$ & $* *$ & $* *$ & $* *$ \\
\hline
\end{tabular}

(1)Produção de colmos referente à 3a soca (safra 2000/2001), em resposta às doses e fontes aplicadas na 2a soca (safra 1999/2000). (2)Produção de colmo e açúcar da $2 \underline{a}+3 \underline{a}$ socas (duas safras consecutivas). **Significativo a $1 \%$ de probabilidade. 
e pol cana $(15,8 \%)$ (Vitti, 2003). Quanto à pol cana $\left(\mathrm{t} \mathrm{ha}^{-1}\right)$, a diferença entre tratamentos foi decorrente apenas da variação significativa na produtividade de colmo por hectare (Tabela 1). Esses resultados confirmaram os obtidos por Azeredo et al. (1986), Orlando Filho et al. (1994), Korndörfer et al. (1997) e Trivelin et al. (2002), significando que a adubação nitrogenada não afetou a qualidade tecnológica dos colmos. Ao mesmo tempo, esses resultados contrariam os de Silveira \& Crocomo (1990), que constataram decréscimo no teor de sacarose em plantas que se desenvolveram na presença de alta concentração de N. A ausência desse efeito neste trabalho, mesmo em doses mais elevadas de $\mathrm{N}$, pode ter como explicação as baixas reservas e a mineralização de N no solo (Vitti, 2003). Outro fator seria quantidades de resíduo orgânico, de alta relação $\mathrm{C}: \mathrm{N}$, que permaneceram no solo após a colheita e que, provavelmente, causaram imobilização microbiológica do $\mathrm{N}$ aplicado e do solo, diminuindo a disponibilidade do nutriente às plantas.

Na Figura 1 são apresentadas correlações positivas, altamente significativas ( $\mathrm{p}<0,01 ; \mathrm{t}_{\text {colmo }}<0,01$ e $\left.\mathrm{t}_{\mathrm{NeS}}<0,01\right)$, para produtividade de colmos na safra 2000/2001 (3 3 soca) e o conteúdo de $\mathrm{N}$ e $\mathrm{S}$ no sistema radicular da cultura ao final da safra 1999/2000 (2a soca), considerados os tratamentos com doses de $\mathrm{N}(0,35,70,105$, 140 e $175 \mathrm{~kg} \mathrm{ha}^{-1}$ ) da fonte NA aplicadas sobre os resíduos culturais de cana-de-açúcar. Quanto ao conteúdo de $\mathrm{N}$, essas variações estiveram relacionadas com a biomassa vegetal do sistema radicular e ao teor de nutrientes. No caso do $S$, a variação foi apenas para a biomassa vegetal.

A resposta de $\mathrm{TCH}$ ao conteúdo de $\mathrm{S}$ nas raízes e rizomas foi 5,3 vezes mais sensível que ao $\mathrm{N}$, ou seja, a cada unidade de $\mathrm{S}$, foi necessário 5,3 unidades de $\mathrm{N}$ para a produtividade de colmos (Figura 1). Esse fator foi obtido pela relação dos coeficientes angulares das retas referente ao $\mathrm{Se} \mathrm{N}$ acumulados no sistema radicular. $\mathrm{O}$ conteúdo de $\mathrm{N}$ nas raízes e rizomas das plantas variou de 22 a $80 \mathrm{~kg} \mathrm{ha}^{-1} \mathrm{e}$, no caso do $\mathrm{S}$, variou de cerca de 4 a $14 \mathrm{~kg} \mathrm{ha}^{-1}$. Esses dois nutrientes foram comparados num mesmo fator - produtividade de colmos - representado pelas ordenadas. No que se refere a esse aspecto, o coeficiente angular da reta (inclinação da reta) para o $\mathrm{N}$ deve ser menor. Nos estudos de marcha de acúmulo de nutrientes pelas culturas, observa-se maior absorção de nitrogênio em relação ao enxofre. Raij \& Cantarella (1997) alcançaram uma relação N:S média de 10 , em folha diagnóstico (folha +1 ) para a cana-deaçúcar, em concentrações consideradas adequadas na região do Estado de São Paulo. No sistema radicular, essa relação foi menor (N:S, 7), o que pode estar relacionado à elevada quantidade de enxofre encontrada nas camadas do solo de 40-60 cm e de 60-80 cm, onde os teores de $\mathrm{S}_{-} \mathrm{SO}_{4}$ foram, respectivamente, de 25 e $50 \mathrm{mg} \mathrm{dm}^{-3}$, ou por ser provavelmente um órgão de reserva da planta. Resultados do vigor de soqueira podem ser um bom instrumento de orientação quanto às adubações de cana-de-açúcar para a safra seguinte, bem como a quantidade de nutrientes presentes no sistema radicular da cultura.

$\mathrm{O} \mathrm{N}$ residual total do fertilizante correspondeu ao somatório do ${ }^{15} \mathrm{~N}$ na forma de $\mathrm{NH}_{4}{ }^{+}\left(\mathrm{N}_{-}{ }^{15} \mathrm{NH}_{4}{ }^{+}\right)$presente no sistema radicular (raízes e rizomas), imobilizado na palha e no solo, ou seja, o $\mathrm{N}$ do fertilizante recuperado no sistema solo-planta (sistema radicular)-palha (Tabela 2). A quantidade de $\mathrm{N}$ residual do amônio, sem levar em consideração o efeito residual do nitrato, da fonte NA representa, para a maior dose de $\mathrm{N}$ aplicado, cerca de $40 \%$ da recomendação atual para soqueira de cana-de-açúcar no Estado de São Paulo que é de
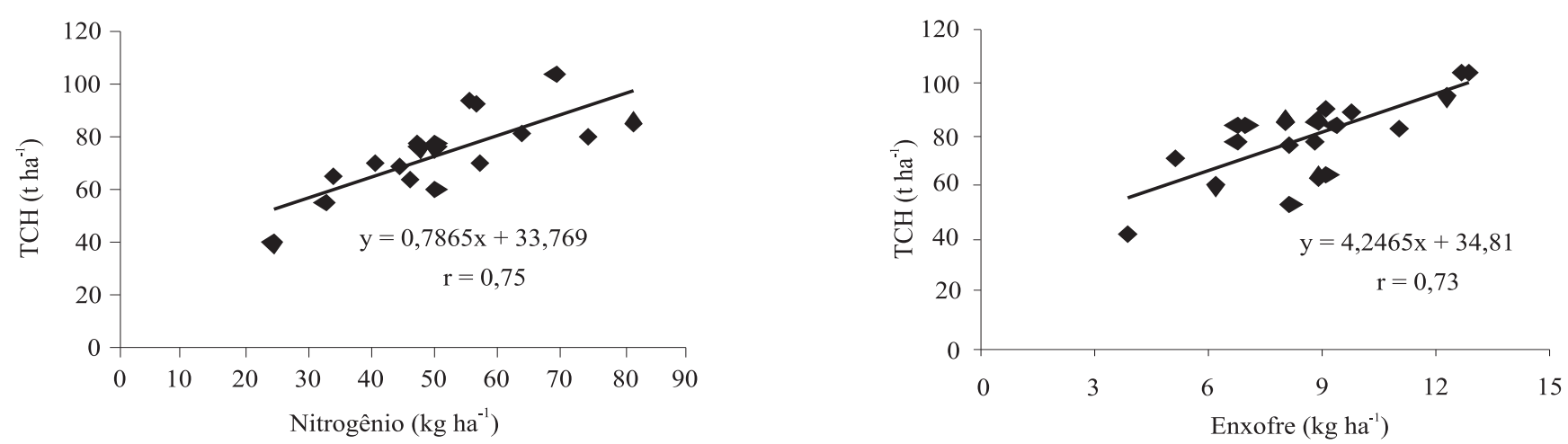

Figura 1. Correlação entre a produção de colmos por hectare (TCH) da 3a soca (safra 2000/2001) e a quantidade total de nitrogênio e enxofre presente no sistema radicular (raízes e rizomas) depois da colheita da 2a soca na safra 1999/2000. 
$100 \mathrm{~kg} \mathrm{ha}^{-1} \mathrm{de} \mathrm{N}$ (Espironello et al., 1997). Por esse efeito residual, pode-se explicar o ganho em produtividade na safra 2000/2001 (3a soca), quando se aplicou dose única de $\mathrm{N}\left(100 \mathrm{~kg} \mathrm{ha}^{-1}\right)$, apresentando resposta linear nas parcelas do primeiro experimento ( $2^{\mathrm{a}}$ soca - safra 1999/2000) que receberam doses crescentes de N (35, $70,105,140$ e $175 \mathrm{~kg} \mathrm{ha}^{-1}$ ).

Constatou-se, também, correlação altamente significativa $\left(\mathrm{p}<0,01 ; \mathrm{t}_{\text {constante }}<0,01\right.$ e $\left.\mathrm{t}_{\mathrm{N} \text {-residual }}<0,01\right)$ entre $\mathrm{o}$ $\mathrm{N}-{ }^{15} \mathrm{NH}_{4}{ }^{+}$residual da fonte NA $\left(\mathrm{kg} \mathrm{ha}^{-1}\right.$ de N$)$ da adubação anterior e a produtividade de colmo $\left(\mathrm{t} \mathrm{ha}^{-1}\right)$ na safra seguinte (Figura 2).

$\mathrm{Na}$ equação da reta da Figura 2, o inverso do coeficiente angular $(0,83)$ da variável $\mathrm{X}$ ( $\mathrm{kg}$ de $\mathrm{N}$ residual) representa o índice de produção de $1,2 \mathrm{~kg}$ de $\mathrm{N}$ residual por tonelada de colmo produzido. Os índices registrados em trabalhos anteriores variam de 0,72 a $1,0 \mathrm{~kg}$ de $\mathrm{N}$ absorvido por tonelada de cana produzida (Andreis, 1975; Orlando Filho et al., 1980). Essas diferenças estão relacionadas à disponibilidade do $\mathrm{N}$ no solo. No caso da realização de adubações nitrogenadas, há maior disponibilidade desse $\mathrm{N}$ do que do $\mathrm{N}$ do fertilizante residual, que pode estar imobilizado pelos microrganismos do solo e, também na forma orgânica no sistema radicular, sendo liberado parcialmente ao longo do ciclo da cultura. As diferenças equivalem ao índice de restituição adotado em determinadas sugestões de adubação, que é de 1 a $1,2 \mathrm{~kg}$ de $\mathrm{N}$ por tonelada de matéria natural produzida (Vitti et al., 2006).
As reservas de $\mathrm{N}$ e $\mathrm{S}$, no sistema radicular, correlacionaram-se diretamente com a produção de colmo na safra seguinte e, por isso, o $\mathrm{N}$ residual do fertilizante no solo, também mostrou correlação positiva. Wiedenfeld (1998) verificou que diferentes culturas, antecedentes à cultura de cana-de-açúcar, e doses de $\mathrm{N}$ aplicadas a essas culturas causaram efeito significativo no acúmulo de $\mathrm{N}$ pela cana-de-açúcar, ou seja, o $\mathrm{N}$ inorgânico do solo correlacionou-se com a quantidade do $\mathrm{N}$ aplicado e com o rendimento da cultura subseqüente.

Os resultados apresentados contêm indicação de que o manejo da adubação nitrogenada da cana-soca em áreas de colheita da cana-de-açúcar sem queima prévia poderá passar por ajustes - possível aumento das doses de $\mathrm{N}$ das adubações - devido à alta relação $\mathrm{C}: \mathrm{N}$ da palhada da cana-de-açúcar depositada na superfície do solo, o que leva à imobilização de $\mathrm{N}$ do solo e do fertilizante (se aplicado) pelos microrganismos, diminuindo sua disponibilidade. Serve como exemplo, a verificação de que houve resposta linear às doses de $\mathrm{N}$, de até $175 \mathrm{~kg} \mathrm{ha}^{-1}$, aplicadas na $2^{\mathrm{a}}$ soca na produtividade da $3^{\mathrm{a}}$ soca, mesmo aplicando-se dose única de $\mathrm{N}$ após a colheita da $2^{\mathrm{a}}$ soca. Se o $\mathrm{N}$ for mantido no sistema, sem ser perdido por volatilização de amônia, lixiviação ou desnitrificação, ele permanecerá no solo formando um estoque com a matéria orgânica, podendo-se reduzir as doses de $\mathrm{N}$ das adubações, com o tempo de implantação do sistema sem queima.

Tabela 2. Recuperação do ${ }^{15} \mathrm{~N}$, na forma de $\mathrm{NH}_{4}{ }^{+}\left(\mathrm{kg} \mathrm{ha}^{-1}\right.$ e em \%), do nitrato de amônio (NA) aplicado em faixa, em cinco doses de nitrogênio, por ocasião da colheita da cana-de-açúcar (2ª soca - safra 1999/2000)(1).

\begin{tabular}{|c|c|c|c|c|c|}
\hline \multirow{2}{*}{$\begin{array}{l}\text { Doses de NA } \\
\left(\mathrm{kg} \mathrm{ha}^{-1} \text { de N) }\right.\end{array}$} & \multicolumn{5}{|c|}{ Recuperação do ${ }^{15} \mathrm{~N}$} \\
\hline & Raiz & Parte aérea & Solo & Palha & Efeito residual $^{(2)}$ \\
\hline & \multicolumn{5}{|c|}{ 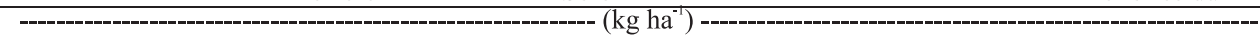 } \\
\hline 35 & $1,0 \pm 0,1$ & $4,2 \pm 0,2$ & $5,4 \pm 0,4$ & $0,8 \pm 0,0$ & $7,2 \pm 0,4$ \\
\hline 70 & $2,0 \pm 0,1$ & $6,8 \pm 0,3$ & $11,9 \pm 0,5$ & $0,8 \pm 0,1$ & $14,7 \pm 0,5$ \\
\hline 105 & $4,9 \pm 1,0$ & $10,5 \pm 1,3$ & $17,5 \pm 2,9$ & $1,3 \pm 0,2$ & $23,7 \pm 3,8$ \\
\hline 140 & $4,4 \pm 0,3$ & $16,6 \pm 2,3$ & $24,5 \pm 0,6$ & $1,3 \pm 0,3$ & $30,1 \pm 0,1$ \\
\hline 175 & $9,6 \pm 0,7$ & $22,3 \pm 1,6$ & $25,7 \pm 1,7$ & $1,1 \pm 0,3$ & $36,4 \pm 1,9$ \\
\hline Regressão linear & $* *$ & $* *$ & $* *$ & $\mathrm{~ns}$ & $* *$ \\
\hline $\mathrm{R}^{2}$ & 0,90 & 0,97 & 0,97 & - & 0,995 \\
\hline \multirow{2}{*}{$\mathrm{CV}(\%)$} & 27,4 & 22,4 & 16,7 & 30,4 & 17,1 \\
\hline & \multicolumn{5}{|c|}{ 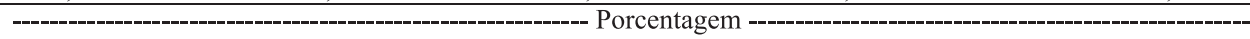 } \\
\hline 35 & $5,5 \pm 1,0$ & $22,8 \pm 1,3$ & $29,5 \pm 2,3$ & $4,4 \pm 0,3$ & $39,3 \pm 2,4$ \\
\hline 70 & $5,6 \pm 0,3$ & $19,0 \pm 0,9$ & $33,4 \pm 1,3$ & $2,2 \pm 0,2$ & $40,8 \pm 1,3$ \\
\hline 105 & $8,9 \pm 1,8$ & $19,2 \pm 2,4$ & $31,8 \pm 5,3$ & $2,4 \pm 0,4$ & $43,2 \pm 7,0$ \\
\hline 140 & $6,0 \pm 0,5$ & $22,7 \pm 3,1$ & $36,3 \pm 3,4$ & $1,7 \pm 0,4$ & $44,0 \pm 2,9$ \\
\hline 175 & $10,5 \pm 0,8$ & $24,4 \pm 1,8$ & $28,2 \pm 1,8$ & $1,2 \pm 0,3$ & $39,8 \pm 2,0$ \\
\hline Média & - & 21,6 & 31,7 & - & 41,4 \\
\hline Regressão linear & $* *$ & ns & $\mathrm{ns}$ & $* *$ & ns \\
\hline $\mathrm{CV}(\%)$ & 26,5 & 19,1 & 15,5 & 22,4 & 15,2 \\
\hline
\end{tabular}

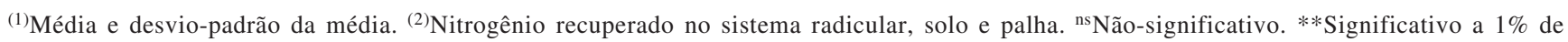
probabilidade. 


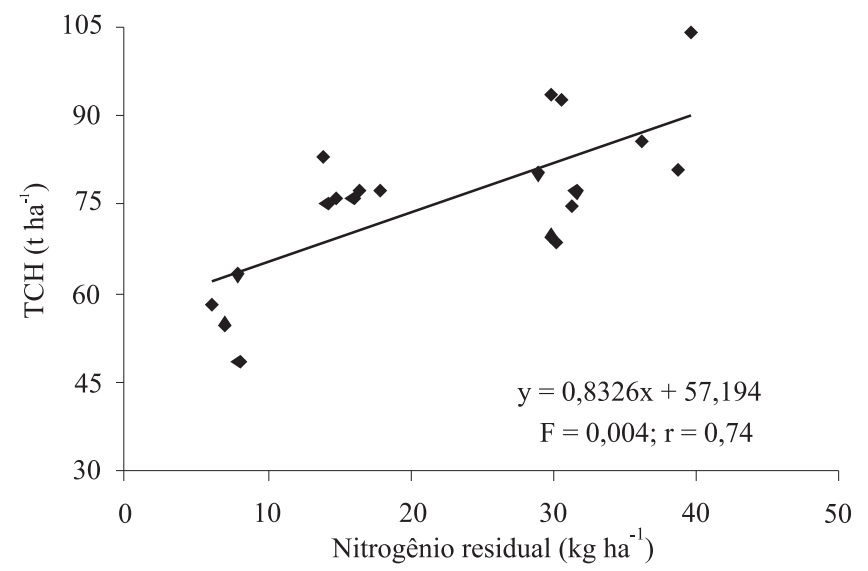

Figura 2. Correlação entre a produção de colmos de cana-deaçúcar $(\mathrm{TCH})$ da 3 a soca e o ${ }^{15} \mathrm{~N}$ residual (sistema radicular, solo e imobilizado na palha) das cinco doses de nitrogênio da fonte nitrato de amônio $\left(\mathrm{kg} \mathrm{ha}^{-1}\right)$, no início do ciclo (safra 2000/2001), após a colheita da 2a soca.

\section{Conclusões}

1. O nitrogênio da fertilização nitrogenada em doses crescentes até $175 \mathrm{~kg} \mathrm{ha}^{-1}$ resulta em aumento linear na produtividade de colmos de uma 2 2 soca; esse efeito se estende para a $3^{\mathrm{a}}$ soca.

2. Em torno de $40 \%$ do amônio da fonte nitrato de amônio permanece no sistema solo-planta (raízes e rizomas)-palha como efeito residual para a safra seguinte, independentemente da dose de nitrogênio aplicada.

3. Os estoques de nitrogênio e enxofre no sistema radicular ao final da $2^{\mathrm{a}}$ soca relacionam-se positivamente com a produtividade de colmos da cana-de-açúcar na 3 soca.

\section{Agradecimentos}

À Fapesp, pela bolsa concedida ao primeiro autor; à Copersucar e à Usina São Luiz do Grupo Dedini/S.A.; pelo apoio logístico.

\section{Referências}

ANDREIS, H.J. Macro and micronutrient content of millable Florida sugar-cane. Sugar Journal, v.37, p.10-12, 1975.

AZEREDO, D.F.; BOLSANELLO, J.; WEBER, H.; VIEIRA, J.R. Nitrogênio em cana-planta - doses e fracionamento. STAB, v.6, p.26-33, 1986.
BARRIE, A.; PROSSER, S.J. Automated analysis of light-element stable isotopes by isotope ratio mass spectrometry. In: BOUTTON, T.W.; YAMSAHI, S. (Ed.). Mass spectrometry of soils. New York: M. Dekker, 1996. p.1-46.

CALDAS, C. Manual de análises selecionadas para indústrias sucroalcooleiras. Maceió: Sindicato da Indústria do Açúcar e do Álcool no Estado de Alagoas, 1998. 422p.

CHAPMAN, L.S.; HOGARTH, D.M.; LEVERINGTON, K.C. Does nitrogen fertilizer carry over to succeeding crops? In: AUSTRALIAN SOCIETY OF SUGAR CANE TECHNOLOGISTS CONGRESS, 22. , 1983, Brisbane. Proceedings. Brisbane: Watson Fergunson, 1983. p.109-114.

EMBRAPA. Centro Nacional de Pesquisa de Solos (Rio de Janeiro, RJ). Sistema brasileiro de classificação de solos. Rio de Janeiro, 1999. 412p.

ESPIRONELLO, A.; RAIJ, B. van; PENATTI, C.P.; CANTARELLA, H.; MORELLI, J.L.; ORLANDO FILHO, J.; LANDELL, M.G.A.; ROSSETTO, R. Cana-de-açúcar. In: RAIJ, B. van; CANTARELLA, H.; QUAGGIO, J.A.; FURLANI, A.M.C. (Ed.). Recomendações de adubação e calagem para o Estado de São Paulo. Campinas: Fundação IAC, 1997. p.237-239. (Boletim, 100).

FERNANDES, A.C. Autorização da colheita da cana-de-açúcar. Piracicaba: Centro de Tecnologia da Copersucar, 1986. 22p.

KORNDÖRFER, G.H.; VALLE, M.R.; MARTINS, M.; TRIVELIN, P.C.O. Aproveitamento do nitrogênio da uréia pela cana planta. Revista Brasileira de Ciência do Solo, v.21, p.23-26, 1997.

MALAVOLTA, E. Fertilizing for high yield sugarcane: nutrient and fertilizer management in sugarcane. Basel: I.P.I., 1994. 104p. (Bulletin, 14).

MALAVOLTA, E.; VITTI, G.C.; OLIVEIRA, S.A. Avaliação do estado nutricional das plantas. Piracicaba: Associação Brasileira para Pesquisa da Potassa e do Fosfato, 1989. 201p.

ORLANDO FILHO, J.; CARMELLO, Q.A.C.; PEXE, C.A.; GLÓRIA, A.M. Adubação de soqueiras de cana-de-açúcar sob dois tipos de despalha: cana crua x cana queimada. STAB, v.1, p.7-11, 1994.

ORLANDO FILHO, J.; HAAG, H.P.; ZAMBELLO JÚNIOR, E. Crescimento e absorção de macronutrientes pela cana-de-açúcar, variedade CB 41-76, em função da idade, em três solos do Estado de São Paulo. Piracicaba: Planalsucar, 1980. 128p. (Planalsucar. Boletim técnico, 2).

ORLANDO FILHO, J.; RODELLA, A.A.; BELTRAME, J.A.; LAVORENTI, N.A. Doses, fontes e formas de aplicação de nitrogênio em cana-de-açúcar. STAB, v.17, p.39-41, 1999.

RAIJ, B. van; CANTARELLA, H. Outras culturas industriais. In: RAIJ, B. van; CANTARELLA, H.; QUAGGIO, J.A.; FURLANI, A.M.C. (Ed.). Recomendações de adubação e calagem para o Estado de São Paulo. Campinas: Fundação IAC, 1997. p.233-243. (Boletim, 100).

SILVEIRA, J.A.G.; CROCOMO, O.J. Assimilação de nitrogênio em cana-de-açúcar cultivada em presença de elevado nível de $\mathrm{N}$ e de 
vinhaça no solo. Revista Brasileira de Fisiologia Vegetal, v.2, p.7-15, 1990.

TRIVELIN, P.C.O.; LARA CABEZAS, W.A.R.; VICTORIA, R.L.; REICHARDT, K. Evaluation of a ${ }^{15} \mathrm{~N}$ plot design for estimating plant recovery of fertilizer of nitrogen applied to sugar cane. Scientia Agricola, v.51, p.226-234, 1994.

TRIVELIN, P.C.O.; VITTI, A.C.; OLIVEIRA, M.W.; GAVA, G.J.C.; SARRIÉS, G.A. Utilização de nitrogênio e produtividade da canade-açúcar (cana-planta) em solo arenoso com incorporação de resíduos da cultura. Revista Brasileira de Ciência do Solo, v.26, p.636-646, 2002.
VITTI, A.C. Adubação nitrogenada da cana-de-açúcar (soqueira) colhida mecanicamente sem a queima prévia: manejo e efeito na produtividade. 2003. 114p. Tese (Doutorado) - Universidade de São Paulo, Piracicaba.

VITTI, G.C.; MAZZA, J.A.; QUINTINO, T.A.; OTTO, R. Nutrição e adubação. In: RIPOLI, T.C.C.; RIPOLI, M.L.C.; CASAGRANDI, D.V.; IDE, B.Y. Plantio da cana-de-açúcar: estado da arte. Piracicaba: Esalq, 2006. p.102-144.

WIEDENFELD, R.P. Previous-crop effects on sugarcane responses to nitrogen fertilization. Agronomy Journal, v.90, p.161-165, 1998.

Recebido em 6 de julho de 2006 e aprovado em 27 de novembro de 2006 